\title{
Intraparenchymal Supratentorial Neurenteric Cyst
}

\author{
Edward Kachur, Lee-Cyn Ang, Joseph F. Megyesi
}

\begin{abstract}
Background: Neurenteric cysts are congenital cysts of the central nervous system that are believed to be of endodermal origin. In this report we present the unique case of a supratentorial neurenteric cyst that is contained entirely within the brain parenchyma. Methods: Apatient presented with an intraparenchymal cystic lesion that was subsequently identified as a neurenteric cyst. This lesion is reviewed in light of the available literature. Case report: A 35-year-old female presented with a one year history of progressive headaches and seizure-like episodes. Her examination revealed no deficits. Magnetic resonance imaging showed a $4 \mathrm{~cm} \mathrm{x} 4 \mathrm{~cm} \mathrm{x} 4 \mathrm{~cm}$ cystic lesion within the parenchyma of the right frontal lobe. A right frontal craniotomy and complete excision of the cystic lesion was performed. Pathologic examination confirmed that it was a neurenteric cyst. Postoperatively the patient's symptoms improved. Conclusion: Review of the literature revealed this to be the first case of a surgically excised, pathologically confirmed supratentorial neurenteric cyst, contained entirely within the brain parenchyma.
\end{abstract}

RÉSUMÉ: Kyste neurentérique supratentoriel intraparenchymateux. Introduction: Les kystes neurentériques sont des kystes congénitaux du système nerveux central qu'on pense être d'origine endodermique. Nous présentons un cas unique de kyste neurentérique supratentoriel situé entièrement dans le parenchyme cérébral. Méthodes: Une patiente a consulté pour un kyste intraparenchymateux qui a été éventuellement identifié comme étant un kyste neurentérique. Nous faisons une révision de la littérature concernant cette pathologie. Cas clinique: Une femme âgée de 35 ans a consulté pour des céphalées progressives depuis un an et des crises épileptiformes. À l'examen clinique, on n'a noté aucun déficit neurologique. L'imagerie par résonance magnétique a montré une lésion kystique de $4 \mathrm{~cm}$ x $4 \mathrm{~cm} \mathrm{x} 4 \mathrm{~cm}$ dans le parenchyme du lobe frontal droit. Elle a subi une craniotomie frontale droite et une excision complète de la lésion kystique. L'examen anatomopathologique a confirmé qu'il s'agissait d'un kyste neurentérique. Les symptômes de la patiente se sont amélioré suite à la chirurgie. Conclusion: Une revue de la littérature a montré qu'il s'agit du premier cas de kyste neurentérique supratentoriel entièrement contenu dans le parenchyme cérébral qui a été excisé et dont le diagnostic a été confirmé à l'examen anatomopathologique.

Can. J. Neurol. Sci. 2004; 31: 412-416

Neurenteric cysts are congenital abnormalities usually found within the posterior mediastinum, ${ }^{1}$ but can occur in the central nervous system (CNS). They are rare congenital cysts with histological features that indicate an endodermal origin. ${ }^{2}$ The cysts are lined by single or multi-layered cuboidal or columnar epithelium. The epithelium may or may not be ciliated and goblet cells are occasionally seen. The epithelium resembles that which lines the respiratory or gastrointestinal tract. ${ }^{2,3}$

Central nervous system neurenteric cysts are most commonly found ventral to the spinal cord in the intradural extramedullary space at the level of the cervical or upper thoracic spine. ${ }^{4}$ Lumbosacral neurenteric cysts have also been reported..$^{5-7}$ The majority of intracranial neurenteric cysts occur in the posterior fossa $^{8,9}$ or at the craniocervical junction. ${ }^{10,11}$ Supratentorial neurenteric cysts are very rare and none of the cysts in those cases reported to date have been located within the brain parenchyma. ${ }^{3,12-19}$ We report a case of a 35-year-old female who underwent successful excision of an intraaxial right frontal lobe neurenteric cyst. To our knowledge, this is the first case report of a surgically excised, pathologically confirmed supratentorial neurenteric cyst, contained entirely within the brain parenchyma.

\section{CASE RePort}

A 35-year-old right handed female presented with a one year history of seizure-like episodes, though she sought medical attention only recently. The seizures were described as a motionless stare that lasted for a few seconds. The patient also complained of increasing right frontal headaches. On examination the patient was alert and cooperative. Her neurological examination was normal. No papilledema was seen. No

From the Division of Neurosurgery, Department of Clinical Neurological Sciences and Department of Pathology, London Health Sciences Centre, University of Western Ontario, London, Ontario, Canada.

Received August 19, 2003. Acceptedin finalform February 5, 2004 Reprint requests to: Joseph F. Megyesi, Division of Neurosurgery, London Health Sciences Centre, 339 Windermere Road, Room 10-OF1, London, Ontario N6A5A5 Canada. 
signs of spinal dysraphism were noted. The patient's only medication was carbamazepine, which she had recently started.

T1-weighted magnetic resonance imaging (MRI) demonstrated a right frontal polar cystic lesion measuring $4 \mathrm{~cm} \mathrm{x} 4 \mathrm{~cm}$ x $4 \mathrm{~cm}$ (Figure 1). The cyst had a low signal intensity on the $\mathrm{T} 1$ sequence and possessed subtle septations with a mildly irregular outline. No enhancement was seen following administration of gadolinium. No edema surrounding the cyst was noted. The cyst was noted to be contained entirely within the brain parenchyma, separate from both the ventricular system and subarachnoid space. The patient underwent a right frontal craniotomy, at which time the entirely intraparenchymal nature of the cyst was verified. The cyst was initially aspirated and a clear yellowish fluid was removed. Cytopathology of the fluid did not reveal the presence of any malignant cells. The cyst wall was excised completely.

The gross specimen consisted of a membranous greyish tan tissue measuring approximately $12.0 \times 1.5 \times 0.2 \mathrm{~cm}$ and another greyish fragment of irregular tissue measuring $0.4 \times 0.2 \times 0.1 \mathrm{~cm}$. The thickness of the tissue was variable with small excavations that appeared translucent. Samples taken from the larger piece for frozen section revealed a benign cyst.

All the submitted tissues were subsequently fixed in $10 \%$ buffered formalin and processed for paraffin sections. Microscopic examination showed a multiloculated cyst lined by one to few cell layers of cuboidal epithelium (Figure 2A). Some of these cells had vacuolated cytoplasm but no typical goblet cells were noted. Sparse cilia were observed. There was no nuclear atypia and mitotic figures were not seen. Meningothelial cell nests were absent. Beneath the epithelial layer there was a narrowed rim of fibrous connective tissue surrounded by brain tissue. The PASdiastase showed the presence of a basement material associated with the epithelium but the epithelium itself did not stain. The subepithelial fibrous tissue was highlighted by Masson's trichrome.

The cyst epithelium was immunoreactive to low molecular weight keratin (CAM 5.2) and cytokeratin, CK 7 (Figure 2B), as well as the epithelial membrane antigen. Chromogranin A-immunoreactivity was also noted in many of the epithelial cells. No immunoreactivity was noted in the epithelial cells with cytokeratin CK20, carcino-embryonal antigen (CEA), glial fibrillary acidic protein (GFAP), synaptophysin, transthyretin (prealbumin), vimentin and S-100 protein. The morphological features and immunophenotypic profile were consistent with a neurenteric cyst. The chromogranin-A immunoreactivity is a feature of foregut epithelium. The absence of transthyretin and GFAPin the cyst lining ruled out a cyst of choroid plexus and neuroepithelial (ependymal) origin. The location of the cyst within the brain substance was unlike that of a colloid cyst, an ependymal cyst or an arachnoid cyst. The absence of meningothelial nests and other elements of the mesoderm and ectoderm was against this being an arachnoid cyst or a cystic teratoma.

The patient did well postoperatively with no complications noted. On a six month postoperative visit the patient's headaches had resolved and her seizures had decreased in frequency and intensity. She will be followed with serial MRI at yearly intervals for a minimum of five years.

\section{DISCUSSION}

Neurenteric cysts have been referred to by various other names including endodermal cyst, enterogenous cyst, neuroenteric cyst, archenteric cyst, gastrocytoma, intestinoma and enteric cyst. . $^{3,11,13,15-18}$ Intracranial neurenteric cysts are more frequent in the posterior fossa in comparison to the supratentorial area. Cyst locations in the posterior fossa include the fourth ventricle, the prepontine space, adjacent to the jugular foramen, the cerebellopontine angle, the cerebellar vermis and within the medulla. ${ }^{2,8,20-23}$ Ten cases of supratentorial neurenteric cysts have been previously reported. Cyst locations include the parasellar/suprasellar region, ${ }^{14,17}$ the septum pellucidum, ${ }^{16}$ the third ventricle ${ }^{3}$ the orbital apex/superior orbital fissure, ${ }^{15}$ the optic nerve, ${ }^{18}$ and the extraaxial anterior cranial fossa ${ }^{12,13,19}$ (Table). None of these cysts was contained within the brain parenchyma.

In our review of supratentorial neurenteric cysts, including the present case, there were six females and five males with a mean age of 33 years (range: 19-49 years). As a comparison, the majority of patients with posterior fossa intracranial neurenteric cysts present in the third to fifth decades (range: birth to 77 years $)^{8,15}$ and there is either a slight male ${ }^{8}$ or a slight female predominance. ${ }^{15}$ Spinal neurenteric cysts can occur over a
A

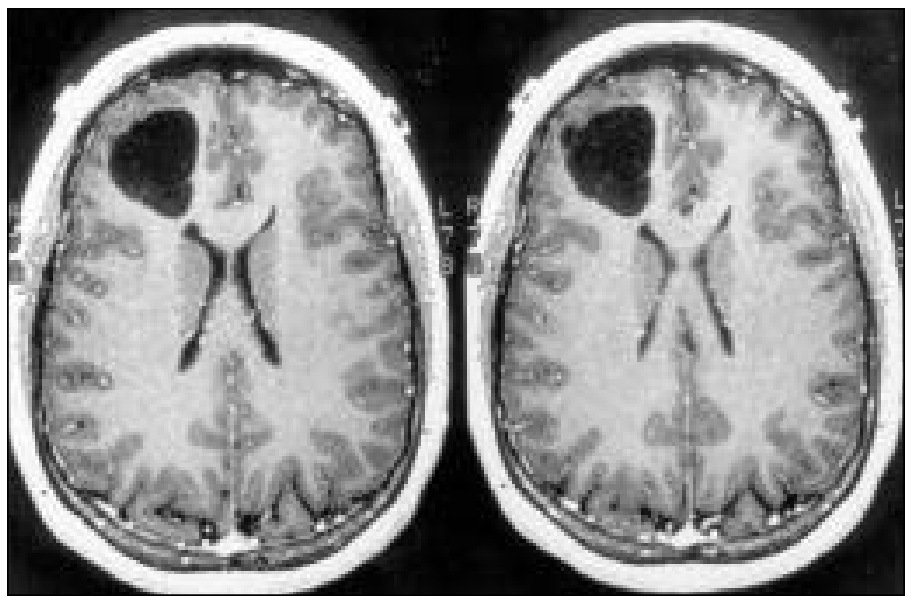

Figure 1A: T1-weighted magnetic resonance imaging scan pre-and post gadolinium enhancement shows a well defined intraparenchymal cyst which signals like cerebrospinal fluid and does not enhance. It is separate from the lateral ventricle.

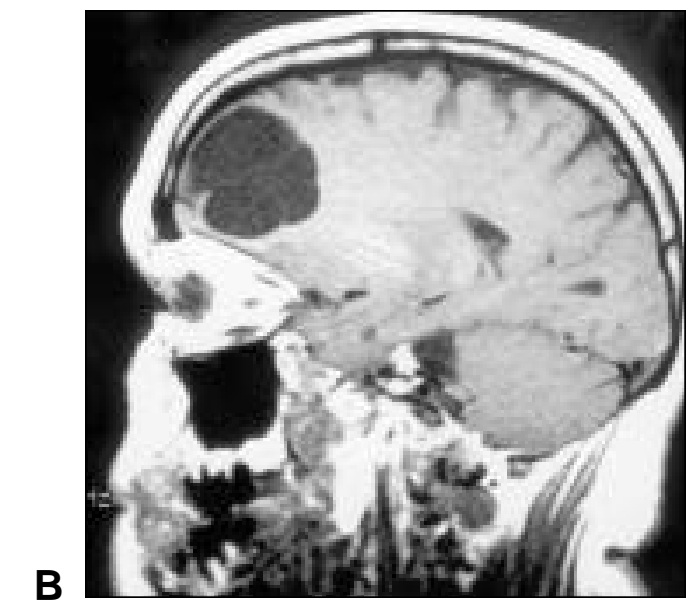

Figure 1B: T1-weighted magnetic resonance imaging scan without contrast demonstrates subtle septations within the cyst. 


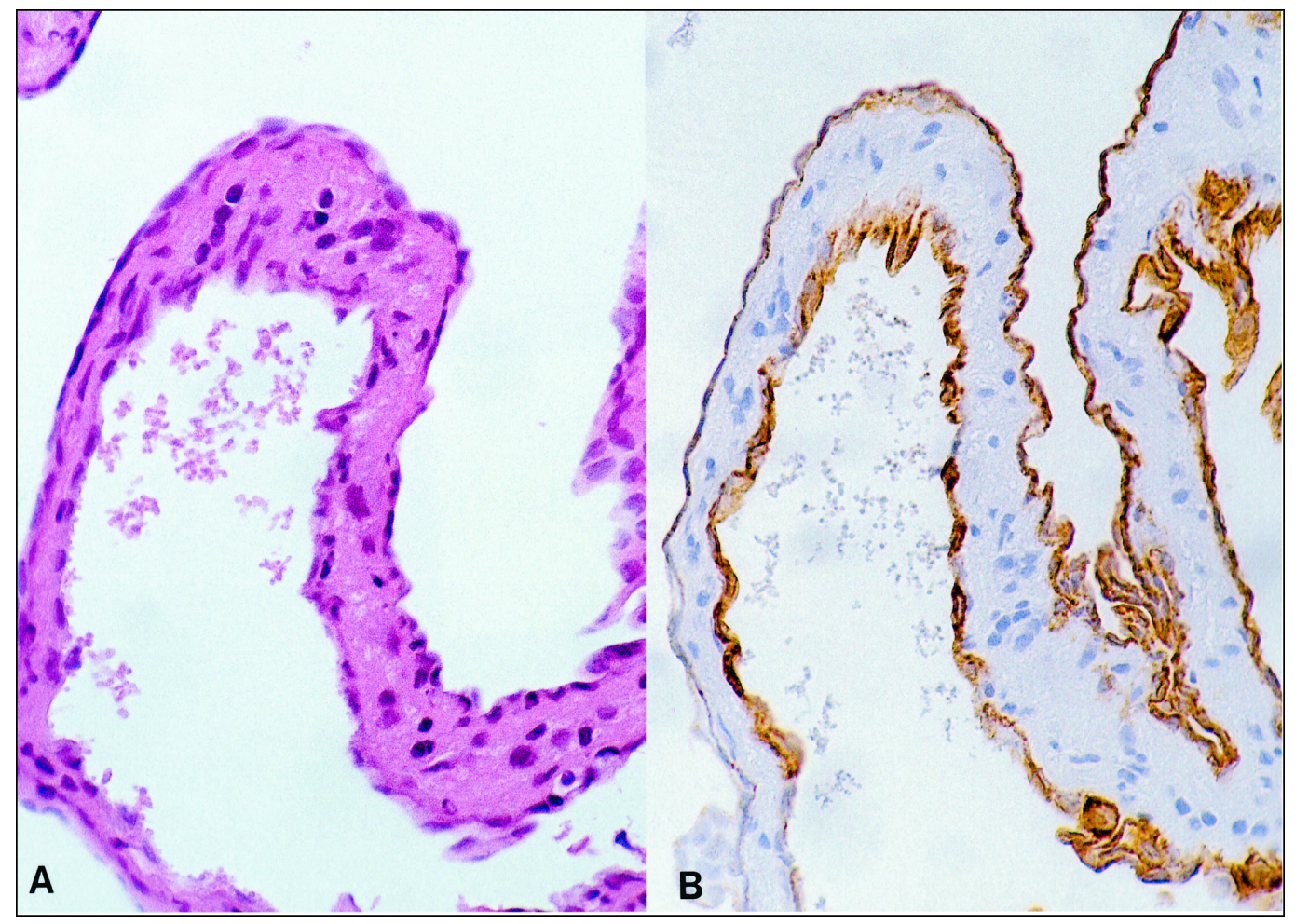

Figure 2A: Single layer of cuboidal epithelium in the multiloculated cyst.

(Masson's trichrome, original magnification x 25).
Figure 2B: Cytokeratin immunoreactivity in the epithelial lining of the cyst. (CK7, original magnification $x 25)$. similar wide range of ages as intracranial cysts but are more common in the pediatric age group and have a distinct 2-3:1 male predominance. ${ }^{4,11}$

The signs and symptoms produced by neurenteric cysts are usually secondary to compression or irritation of surrounding neural structures (Table). There is usually a long history of symptoms that progress over months to years with an acute worsening once the cyst reaches a critical size. ${ }^{3,16}$ Alternatively, some intracranial and spinal neurenteric cysts may present with a fluctuating course of episodic symptoms that have occasionally led to a misdiagnosis of multiple sclerosis. ${ }^{11,17,21,24}$ Intermittent leakage of cyst contents may explain the fluctuating symptoms. Furthermore, cyst leakage has been known to cause meningeal irritation and infection. ${ }^{11}$ The case presented in this report and the cases presented by Bavetta et $\mathrm{al}^{12}$ and Cheng et $\mathrm{al}^{13}$ have all involved intracranial cysts that were diagnosed only when they reached a very large size $(4-5 \mathrm{~cm})$. This is probably due to their frontal location.

Characteristic imaging features of intracranial posterior fossa neurenteric cysts include well-defined borders, lack of contrast enhancement, and a variety of intensities seen on T1 and T2 weighted MRI.,21,22,25 Magnetic resonance signal intensity is influenced by the protein content and the presence of hemorrhage and fat within the cyst. ${ }^{11,21,22}$ The lesions are avascular on cerebral angiograms. ${ }^{8,21,22,25}$ Supratentorial cysts have similar imaging characteristics to their posterior fossa counterparts. The neurenteric cyst presented in this case possessed the signal characteristics of cerebrospinal fluid (Figure
1). This has been described with other intracranial neurenteric cysts. ${ }^{12,25}$ No edema or enhancement was seen.

The complete excision of symptomatic intracranial neurenteric cysts, including removal of the cyst wall, is the treatment choice. ${ }^{8,9,11,22}$ The majority of previously reported supratentorial neurenteric cysts were completely excised on initial treatment (9/10 cases) with improvement or no worsening of the preoperative condition of the patient (Table). None of these cysts have recurred. Subtotal excision has resulted in recurrences in the supratentorial ${ }^{15}$ and infratentorial space. ${ }^{9}$ Occasionally subtotal resection is necessary because of the proximity of the cyst to cranial nerves or because of difficult locations to access such as the anterior brainstem. ${ }^{8,9,11,22}$

The differential diagnosis of neurenteric cysts includes other cystic lesions such as ependymal cysts, Rathke's cleft cysts, colloid cysts, arachnoid cysts and teratomatous cysts. A metastatic tumor should also be considered in the differential diagnosis of a supratentorial intraparenchymal cystic lesion. The immunohistochemical staining of neurenteric cysts supports an endodermal origin. ${ }^{17}$ Neurenteric cysts stain positive for cytokeratin markers, and are negative for neuronal and ectodermal markers such as GFAP, S-100, neuron specific enolase and synaptophysin. ${ }^{3,13,14}$ Neurenteric cysts are usually, but not always, positive for CEA which is a marker of the embryonic gastrointestinal tract. ${ }^{2,14}$ Ependymal cysts react positively for GFAP and negative for cytokeratin and CEA. ${ }^{10}$ Ependymal cysts also lack a basement membrane on the epithelial lining which is present in neurenteric cysts. ${ }^{9}$ 
Table: Review of the literature: supratentorial neurenteric cysts

\begin{tabular}{|c|c|c|c|c|c|}
\hline Series \& Ref. No. & $\begin{array}{l}\text { Age } \\
(\mathbf{y r}) / \text { Sex }\end{array}$ & Location & Presentation & Treatment & Outcome $^{\text {a }}$ \\
\hline Bavetta et al $1996^{12}$ & $28 / \mathrm{M}$ & $\begin{array}{l}\text { Anterior cranial fossa/ } \\
\text { extraaxial }\end{array}$ & Seizure & Craniotomy - complete excision & good \\
\hline Büttner et al $1997^{3}$ & $28 / \mathrm{M}$ & 3rd ventricle & $\begin{array}{l}\text { Headache, visual } \\
\text { loss,paraparesis }\end{array}$ & Craniotomy - complete excision & fair \\
\hline Graziani et al $1995^{14}$ & $39 / \mathrm{F}$ & Suprasellar & Amnesia & Craniotomy - complete excision & fair \\
\hline Graziani et al $1995^{14}$ & $40 / \mathrm{F}$ & Suprasellar \& retrosellar & Headache & Craniotomy - complete excision & good \\
\hline Mishra et al $2000^{16}$ & $19 / \mathrm{F}$ & Septum pellucidum & Hydrocephalus & Craniotomy - complete excision & good \\
\hline Sampath et al $1999^{17}$ & $27 / \mathrm{M}$ & Parasellar & $\begin{array}{l}\text { Headache, visual loss, } \\
\text { CN III, V deficits }\end{array}$ & Craniotomy - complete excision & fair \\
\hline Scaravilli et al $1992^{18}$ & $36 / \mathrm{M}$ & Optic nerve & Visual loss & $\begin{array}{l}\text { Craniotomy - optic nerve/cyst } \\
\text { excised }\end{array}$ & fair \\
\hline
\end{tabular}

a Good outcome refers to resolution of, or significant improvement in, preoperative condition.

Fair outcome refers to no change in, or slight improvement of, preoperative condition.

b Surgery by Lynch incision technique.

c STR - Subtotal removal cyst wall.

d Only small amount of presumed cyst fluid removed.

Differentiation from teratomatous cysts is controversial ${ }^{26}$ but the presence of bone, cartilage and positive Barr bodies in teratomatous lesions may aid in the diagnosis. ${ }^{20}$

Controversy also surrounds the issue of differentiating neurenteric cysts from colloid cysts and Rathke's cleft cysts. These three cystic lesions have been stated to be indistinguishable on pathological grounds. ${ }^{17}$ Büttner et al, ${ }^{3}$ however, stated that colloid cysts are usually one-layered without cilia and immunonegative for CEA and thus are differentiated from neurenteric cysts which usually possess more than a single- layer, are intermittently ciliated, and are immunopositive for CEA. This was the basis for their diagnosis of a third ventricular cyst as a neurenteric cyst rather than a colloid cyst. ${ }^{3}$ Although neurenteric cysts usually are positive for CEA, this is not a universal finding, as in our case and others. ${ }^{8,10}$ Electron microscopy may be helpful in the diagnosis of neurenteric cysts ${ }^{27}$ though it was not performed in this case.

The origin of neurenteric cysts in the CNS must explain the presence of a lesion of endodermal origin in neuroectodermal tissue. The ectoderm overlies the endoderm and is separated first 
by the notochordal process then by the definitive notochord during the third week of development. ${ }^{28}$ The abnormal development of this process may lead to the formation of spinal and posterior fossa neurenteric cysts. Ectopic endodermal elements could arise from abnormal adhesions between the endoderm and notochordal process. ${ }^{29}$ A persistent endodermal remnant in the ectoderm may also originate during the second week of development when the epiblast (the future ectoderm) and hypoblast (the future endoderm) are in contact before the invagination of the notochord between these layers. ${ }^{30}$ Bremer $^{31}$ proposed that an accessory neurenteric canal forms through which dorsal herniation of endoderm through a split notochord allows remnants to locate in the neuroectoderm. These theories are supported by the associated anomalies of the vertebra and spinal dysraphic states which are seen with spinal neurenteric cysts. ${ }^{21}$

The origin of supratentorial cysts is difficult to explain by these theories because the most rostral extent of the endoderm occurs at the level of the clivus. ${ }^{17}$ Different explanations for their formation have thus been proposed. Graziani et al ${ }^{14}$ suggested that suprasellar neurenteric cysts, Rathke's cleft cysts, and colloid cysts arise from Seessel's pouch which is an outpouching of the oropharyngeal membrane in the 42-day-old embryo. ${ }^{14}$ Seessel's pouch regresses in humans but forms the adenohypophysis in inferior vertebrates. ${ }^{14}$ The final location of the Seessel's pouch remnant will determine its name. ${ }^{14} \mathrm{~A}$ presellar or retrosellar cyst would be called a neurenteric cyst whereas a cyst in the third ventricle would be referred to as a colloid cyst and an intrasellar cyst would be a Rathke's cleft cyst. ${ }^{14}$ The explanation for the formation of a neurenteric cyst in the frontal lobe is as yet uncertain. The endodermal tissue may arise by way of a yet undermined process of anomalous differentiation of ectodermal tissue. ${ }^{14}$ Also, it may be possible that further migration of Seessel's pouch remnants as far as the frontal lobe may occur. ${ }^{14}$

Central nervous system neurenteric cysts are found most often in the spine, posterior fossa, and only rarely in the supratentorial space. Supratentorial neurenteric cysts are found in a variety of extraparenchymal locations and good surgical results are obtained with complete excision. This case of a supratentorial, entirely intraparenchymal, neurenteric cyst adds to the complexity of the understanding of this entity.

\section{ACKNOWLDEGEMENTS}

The authors thank Judy Butler for her expert assistance in the preparation of this manuscript. This work was supported by a Chiron Research Donation.

\section{REFERENCES}

1. French BN. The embryology of spinal dysraphism. Clin Neurosurg 1983; 30: 295-340.

2. Inoue T, Matsushima T, Fukui M, et al. Immunohistochemical study of intracranial cysts. Neurosurgery 1988; 23: 576-581.

3. Büttner A, Winkler PA, Weis S. Endodermal cyst of the third ventricle: case report. Neurosurgery 1997; 40: 832-835.

4. Wilkins RH, Odom GL. Spinal intradural cysts. In: Vinken PJ, Bruyn GW, (Eds). Handbook of Clinical Neurology: Tumors of the Spine and Spinal Cord - Part II. Amsterdam: North-Holland, 1976: Vol 20, 55-102.

5. Arai Y, Yamaguchi Y, Tsuji T, et al. Spinal neurenteric cyst: report of two cases and review of forty-one cases reported in Japan. Spine 1992; 17: 1421-1424.
6. LeDoux MS, Faye-Petersen OM, Aronin PA, Vaid YN, Pitts RM. Lumbosacral neurenteric cyst in an infant: case report. J Neurosurg 1993; 78: 821-825.

7. Mendel E, Lese GB, Gonzalez-Gomez I, Nelson MD, Raffel C. Isolated lumbosacral neurenteric cyst with partial sacral agenesis: case report. J Neurosurg 1994; 35: 1159-1163.

8. Bejjani GK, Wright DC, Schessel D, Sekhar LN. Endodermal cysts of the posterior fossa: report of three cases and review of the literature. J Neurosurg 1998; 89: 326-335.

9. Eyon-Lewis NJ, Kitchen N, Scaravilli F, Brookes GB. Neurenteric cyst of the cerebellopontine angle: case report. Neurosurgery 1998; 42: 655-658.

10. Fuse T, Yamada K, Kamiya K, Inagaki H. Neurenteric cyst at the craniovertebral junction: report of two cases. Surg Neurol 1998; 50: 431-436.

11. Menezes AH, Ryken TC. Craniocervical intradural neurenteric cysts. Pediatr Neurosurg 1995; 22: 88-95.

12. Bavetta S, El-Shunnar K, Hamlyn PJ. Neurenteric cyst of the anterior cranial fossa. Br J Neurosurg 1996; 10: 225-227.

13. Cheng JS, Cusick JF, Ho K-C, Ulmer JL. Lateral supratentorial endodermal cyst: case report and review of literature. Neurosurgery 2002; 51: 493-499.

14. Graziani N, Dufour H, Figarella-Branger D, et al. Do the suprasellar neurenteric cyst, the Rathke cleft cyst and colloid cyst constitute a same entity? Acta Neurochir (Wien) 1995; 133: 174-180.

15. Leventer DB, Merriam JC, Defendini R, et al. Enterogenous cyst of the orbital apex and superior orbital fissure. Ophthalmology 1994; 101: 1614-1621.

16. Mishra GP, Sharma RR, Musa MM, Pawar SJ. Endodermal cyst of septum pellucidum and pregnancy: a case report. Surg Neurol 2000; 53: 583-585.

17. Sampath S, Yasha TC, Shetty S, Chandramouli BA. Parasellar neurenteric cyst: unusual site and histology: case report. Neurosurgery 1999; 44: 1335-1338.

18. Scaravilli F, Lidov H, Spalton DJ, Symon L. Neuroenteric cyst of the optic nerve: case report with immunohistochemical study. J Neurol Neurosurg Psychiatry 1992; 55: 1197-1199.

19. Walls TJ, Purohit DP, Aji WS, Schofield IS, Barwick DD. Multiple intracranial enterogenous cysts. J Neurol Neurosurg Psychiatry 1986; 49: 438-441.

20. Filho FL, Tatagiba M, Carvalho GA, et al. Neurenteric cysts of the craniocervical junction: report of three cases. J Neurosurg (Spine) 2001; 94: 129-132.

21. Harris CP, Dias MS, Brockmeyer DL, et al. Neurenteric cysts of the posterior fossa: recognition, management and embryogenesis. Neurosurgery 1991; 29: 893-898.

22. Malcolm GP, Symon L, Kendall B, Pires M. Intracranial neurenteric cysts: report of two cases. J Neurosurg 1991; 75: 115-120.

23. Zalatnai A. Neurenteric cyst of the medulla oblongata - a curiosity. Neuropediatrics 1987; 18: 40-41.

24. Vinters HV, Gilbert JJ. Neurenteric cysts of the spinal cord mimicking multiple sclerosis. Can J Neurol Sci 1981; 8: 159-161.

25. Chaynes P, Thorn-Kany M, Sol JC, et al. Imaging in neurenteric cysts of the posterior cranial fossa. Neuroradiology 1998; 40: 374-376.

26. Morita Y. Neurenteric cyst or teratomatous cyst. J Neurosurg 1994; 80: 179 (Letter).

27. Hirai O, Kawamura J, Fukumitsu T. Prepontine epithelium-lined cyst: case report. J Neurosurg 1981; 55: 312-317.

28. Sadler TW. Trilaminar germ disc (third week of development). In: Gardner JN, (Ed). Langman's Medical Embryology. Baltimore: Williams and Wilkins, 1990: 50-60.

29. Fallon M, Gordon ARG, Lendrum AC. Mediastinal cysts of foregut origin associated with vertebral anomalies. Br J Surg 1954; 41: 520-533.

30. Beardmore HE, Wiglesworth FW. Vertebral anomalies and alimentary duplications. Pediatr Clin North Am 1958; 5: 457473.

31. Bremer JL. Dorsal intestinal fistulae; accessory neurenteric canal; diastematomyelia. AMAArch Path 1952; 54: 132-138. 